\title{
Hump-nosed Pit Viper Bite in Central Kerala-Remonstrance to Big4 Theory in Snake Bite Envenomation
}

\author{
Aby Paul ${ }^{1 *}$, Dona Johnson ${ }^{1}$, Swapna Saju ${ }^{1}$ and Antriya Annie Tom ${ }^{2}$ \\ ${ }^{1}$ Nirmala College of Pharmacy, Muvattupuzha, Kerala, India \\ ${ }^{2}$ Assistant Professor, Department of Pharmacy Practise, Nirmala College of Pharmacy, Muvattupuzha, Kerala, India \\ *Corresponding Author: Aby Paul, Nirmala College of Pharmacy, Muvattupuzha, Kerala, India.
}

Received: May 07, 2019; Published: July 10, 2019

DOI: $10.31080 /$ ASPS.2019.03.0333

\begin{abstract}
The main aim of the study is the find the impact of the hump nose pit viper in central kerala.

Keywords: Hump-nosed; Snake; Pit Viper
\end{abstract}

\section{Introduction}

Snakebite envenomation is one of the important and undefined occupational health hazard affecting the poor economic people worldwide. The issue is much worse in the tropical part of the world. India is one of the country which is having higher incidence of snake bite. Polyvalent antivenom (ASV) effective against 4 big snakes (Russels viper, Cobra, Krait and Saw scaled viper) is the first line agent of snake bite treatment in these areas. But in these years the involvement other local species like (hump nose pit viper in south India and Srilanka) has earned a attention in this area [1]. Hence there is need of more involved studies to analyse the clinical manifestation and the treatment given for these Hump nose pit viper bite cases in these areas in the absence of an effective antidote.

\section{Methodology}

The study was a multi center hospital-based observational study carried out for 12 months (2017 Jan-1 to 2017 Dec 31).

Inclusion criteria

- A proven case of pit viper bite

- $\quad$ Age: 15 years and above

A proven case is defined as those bite cases in which the snake has been brought and has been identified as pit viper by the investigator.

\section{Statistical analysis}

The descriptive statistics analysis were used to describe the quantitative variables using MS excel 2007.

\section{Results and Discussion}

Out of 144 cases of snakebites reported to the hospital, pit vipers were responsible of which 12 cases were included applying the inclusion criteria.

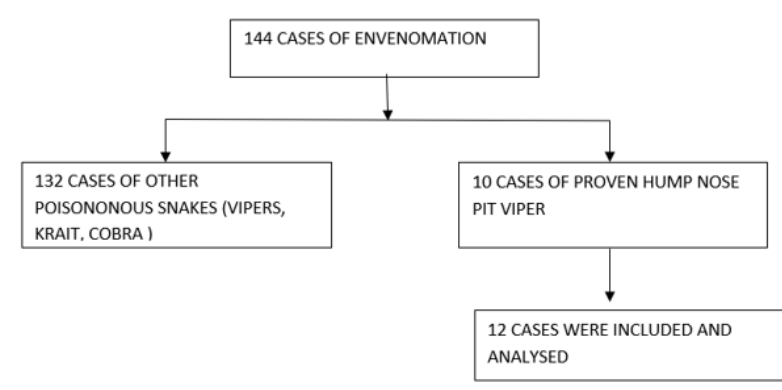

Figure 1

Regional wise distribution of hump nose Pit viper

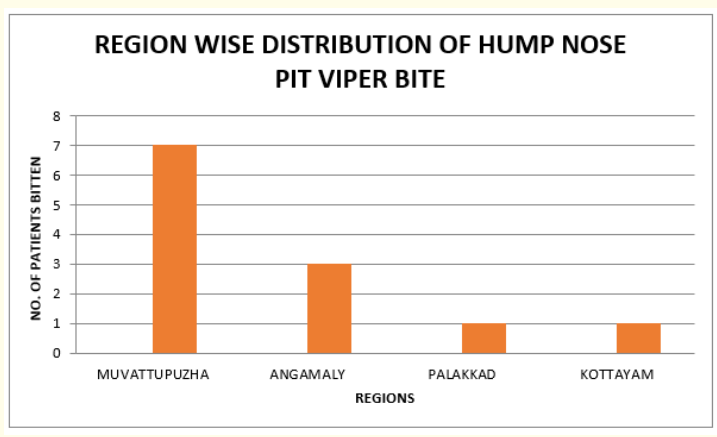

Figure 2 
Hump nose pit viper was predominantly seen in the Muvattupuzha and Angamaly region of central Kerala. This may be related to the diverse geographical area of grass lands and mountain regions, Rubber plantations

\section{Epidemiology}

The mean age of patients who were inflicted by hump nose pit viper is $44( \pm 15.8)$ Bite was equally distributed in both gender (50\% male $50 \%$ female) Attributed to the working population of the region $66.6 \%$ of bite was on the hand and $33.3 \%$ of bite was on the leg, hand was the major site of bite because of camouflage of snake texture. Bite to needle time for the patient to reach the 116.27 minutes (112.7).

\section{Clinical presentation of hump nose PIT viper}

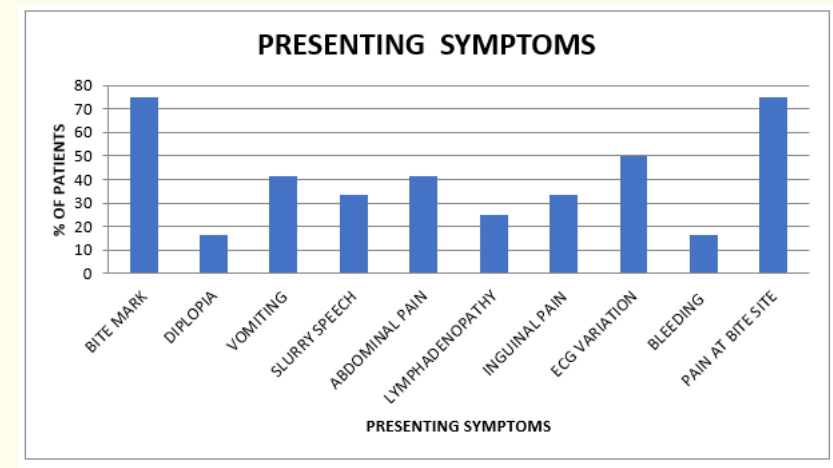

Figure 3

A definite bite mark was observed in $75 \%$ of cases. Although it belongs to a viperidae family bleeding from the bite site was observed in $16.7 \%$ of cases whereas other patients didn't show any bleeding manifestations. The most common clinical outcome of HNV bites in Involvement of pain at bite site. Vomiting and abdominal pain were second leading manifestation about 30\% people showed these symptoms.

20 mint WBCT remained normal in all subjects throughout the hospital stay. Two subjects showed a raised clotting time which was not normalising even after ASV administration. But Fresh frozen plasm (FFP) infusion showed normalization of the raised clotting time within 12 hours in these patients. For other subjects, the clotting time remained prolonged for many days. One subject had a raised PT and APTT at the time of hospitalisation, in 8 case PT showed significant raise in $2^{\text {nd }}$ day.
Out of 12 patients admitted cases, 8 had marked variation in their coagulation in the hospital.during hospital stay. But none showed any clinical evidence of bleeding. The mean delay in onset of coagulopathy was $24.3 \pm 8.4$ hours after the bite. The mean duration of coagulopathy was $5.4 \pm 2.95$ days

INR predominantly raised in 8 patients on the $2^{\text {nd }}$ day of admission with a mean of 3.8 , yet none of them had any bleeding manifestations.

With regard to renal function 4 patients met the criteria for acute kidney injury (AKI). The patient with AKI had a normalized serum creatinine after 4 days of the bite.

Cellulites was seen in 4 patients. Independent $t$ test was done to check for the association between age, delay in reaching hospital, TLC at admission and platelet count with coagulopathy but were not statistically significant [2-5].

Treatment provided

- Anti snake venom treatment were given as the first line agent, Mean use of 15 vials ( \pm 8.2 vials) were used to treat the patients. Out of which $58.3 \%$ showed coagulopathy symptoms and marked elevation of the INR

- $\quad$ Fresh frozen plasma was used in all those patients who showed coagulopathy and was proven effective to correct the deranged value

- $\quad$ Corticosteroids and pencilin class of antibiotics are mainly used for symptomatic relief.

\section{Conclusion}

At this part of the country hump nose pit viper envenomation is a serious issue. There is higher need of an effective antidote to deal in such situations.

\section{Limitation of Our Study}

Sample size of our study was very less for making an effective comparison different perspectives.

\section{Bibliography}

1. Sellahewa K. "Hump-nosed Pit Viper Bite in Sri Lanka? Unravelling an Enigma”. Journal of Tropical Diseases (2013): 01-03.

2. Ariaratnam C., et al. "Frequent and potentially fatal envenoming by hump-nosed pit vipers (Hypnale hypnale and H. nepa) in Sri Lanka: lack of effective antivenom". Transactions of The Royal Society of Tropical Medicine and Hygiene 102.11 (2008): 1120-1126. 
3. Premawardena AP., et al. "Excessive fibrinolysis: The coagulopathy following Merrem's hump-nosed viper (Hypnale hypnale) bites". The American Journal of Tropical Medicine and Hygiene 58 (1998): 821-823.

4. Wijewantha H and Sellahewa K. "Hump nosed viper bite in Sri Lanka-descriptive observational study of 1543 cases”. Asian Pacific Journal of Tropical Medicine 3.11 (2010): 902-905.

5. Maduwage K., et al. "Hump-nosed pit viper (Hypnale hypnale) envenoming causes mild coagulopathy with incomplete clotting factor consumption". Clinical Toxicology 51.7 (2013): $527-$ 531.

Volume 3 Issue 8 August 2019

(C) All rights are reserved by Aby Paul., et al. 